\title{
Percutaneous Pedicle Screw Fixation in Management of Dorsal and Lumbar Fracture Spine
}

\author{
EL-GOHARY M. EL-GOHARY, M.D.*; MOHAMED A.S. SAWAN, M.D.*; MOHAMED F. IBRAHIM, M.D.*; \\ AHMED M. ALI, M.D.* and MOHAMED S.A. AZIZ, M.D.**
}

The Department of Neurosurgery, Faculty of Medicine, Cairo* and Beni Seuf** Universities

\begin{abstract}
Background: Percutaneous pedicle screw fixation is a minimally invasive spine surgery offers patients the benefits of decreased blood loss, fewer complications, and a more rapid return to daily activity.

Aim of Study: To evaluate the percutaneous fixation as regard surgical procedure in the management of unstable dorsal and lumbar spine fracture and the clinical outcome.

Patients and Methods: This study included 30 patients with traumatic thoracolumbar fractures. These patients were treated by percutaneous pedicle screw fixation. This study was conducted in Cairo University Hospitals from June 2011 to February 2014. They were neurologically free.

Results: This series consist of 30 patients presenting with wedge and burst fractures of thoracic and lumbar spine (D12L4). They were treated with percutaneous fixation. These patients were assessed pre-operative and post-operative looking into following points: (A) Clinical and functional assessment; (B) Radiological assessment (C) Intraoperative post-operative complication.

Conclusion: Percutaneous spine fixation is a safe technique for treatment of thoracolumbar wedge and burst fractures with no neurological affection. It has the advantage of short time surgery, no blood loss, no muscle damage. Moreover, short hospital and bed stay are important benefits of percutaneous spine fixation.
\end{abstract}

Key Words: Vertebrae - Percutaneous - Screw - Fixation.

\section{Introduction}

STANDARD techniques for pedicle screw fixation of the lumbar spine involve open exposures and extensive muscle dissection. The percutaneous posterior fixation of the lumbar spine is an existing lumbar pedicle screw system is modified to allow screws to be placed percutaneously [1].

Percutaneous pedicle screw fixation is a minimally invasive spine surgery offering patients the

Correspondence to: Dr. Mohamed Saad Abd El-Aziz, E-Mail: saad1652@gmail.com benefits of decreased blood loss, fewer complications, and a more rapid return to daily activity [2] There are two percutaneous systems.

To evaluate the percutaneous fixation as regard surgical procedure in the management of unstable dorsal and lumbar spine fracture and the clinical outcome.

\section{Patients and Methods}

This study included 30 patients with traumatic thoracolumbar fractures. These patients were treated by percutaneous pedicle screw fixation. This study was conducted in Cairo University Hospitals from June 2011 to February 2014. They were neurologically free.

Inclusion criteria included unstable wedge or burst fractures, more than $30 \%$ anterior height loss, patients with no neurological deficits, canal encroachment must be less than $67 \%$ and gains score (load sharing classification) less than 7 .

Exclusion criteria included fracture dislocation, neurological affection, canal encroachment more than $67 \%$ because higher grades are associated with posterior longitudinal ligament injury and rupture of annulus.

\section{A- Pre-operative evaluation:}

Each patient is evaluated clinically, radiologically and by other pre-operative laboratory investigations to confirm fitness for general anaesthesia.

1- Clinical evaluation: History taking, examination: General and spine examination.

2- Neurological evaluation: Sensory examination (superficial and deep sensation), motor examination for muscle power, reflexes (superficial, deep). 


\section{3- Radiological evaluation: Plain X-ray and CT.}

4- Pre-operative investigations include: Complete Blood Picture (CBC), PTT, INR, liver profile (AST, ALT), renal functions (serum creatinine, urea), ECG and Chest X-rays.

5- There were 2 systems used for percutaneous fixation includes:

A- Sextant system include cannulated screws, rods, screw extender assembly, Rod Inserter and Rod Trocar, rod templates, Tap, and Dilators (three dilators are used).

B- WSH system of Neuro-France include: Cannulated screws, Plates, Dilators, Plate dissector, Plate holder.

\section{Operative technique:}

In our cases all patients had general anaesthesia. while lying supine beside the operating table. All patients were operated on prone position on special radio-translucent table. The patient was placed on special radiotranslucent frame where the injured area was clear for $\mathrm{C}$-arm to take images. The frame makes the patient more stable and abdomen hang free during surgery. The incision sites were marked by permanent marker after identification of pedicles of above and below vertebras using the $\mathrm{C}$-arm in antero-posterior view. The site of incision was in lateral half of the pedicle. Sterile needles were placed in entry points and C-arm image confirmed the direction and site of incision being in lateral half of pedicle in C-arm image. Make sure that Carm shows the body in antero-posterior and lateral views. Incision: A longitudinal skin incision was made at the pedicular site localized by the $\mathrm{C}$-arm image ( $2 \mathrm{~cm}$ each).

Pedicle screw entry and wire passing by using large trocar (starter) and cannula. The C-arm is placed in lateral view from under the patient. If needle position is accepted it is continued till posterior $1 / 4$ th of the body. If not little backward traction then readjustment of the angle in sagittal plane and then gentle push till reach the posterior $1 / 4$ th of body. The needle slides from the short end to long one. So, when we used the bevelled ended needle we started with the long end medially at the same entry point. Then gentle oscillatory movement is applied. If the needle comes near the medial cortex before it reaches the posterior aspect of the body, we rotate the needle $180^{\circ}$ then go away from the medial aspect then we return $180^{\circ}$ again so we would pass away from the medial cortex and still converging for good screw placement. We remove the trocar from the Jamshidi-needle and pass a wire through the cannula till it reaches the anterior
$1 / 2$ of the body to get a good bone grip. The inner trocar of the needle is removed to allow the guide wire to be inserted into the pedicle. Unintentional advancement of the wire can be potentially dangerous. Once the guide wire is inserted, the needle is removed.

Dilators: We remove the cannula of the Jamshidi-needle and hold the wire in place. The fascia and muscle must be dilated to allow for screw placement the Sextent rod system was used in 21 cases $70 \%$. The WSH (plate) system was used in 9 cases $30 \%$. Wound closure.

\section{Post-operative care:}

All patients were neurologically tested, thoracolumbar or lumbar orthosis after the surgery. No movement restriction all patients were instructed to wear their brace during movement and take it off before going to sleep. Patients with fracture spine only were discharged from hospital after 4 days.

The early follow-up study includes: Clinical examination for neurological affection. Postoperative radiology: (A) Plain X-rays: Vertebral body angle, local kyphosis, and Wedge index. (B) Computed tomography: Mid sagittal diameter neural canal after posterior fixation, correction of deformity and pedicle screws site.

\section{Results}

This series consist of 30 patients presenting with wedge and burst fractures of thoracic and lumbar spine (D12-L4). They were treated with percutaneous fixation. These patients were assessed pre-operative and post-operative looking into following points: (A) Clinical and functional assessment, (B) Radiological assessment and (C) Intraoperative post-operative complication.

\section{Clinical and functional assessment:}

Pre-operative clinical and radiological findings.

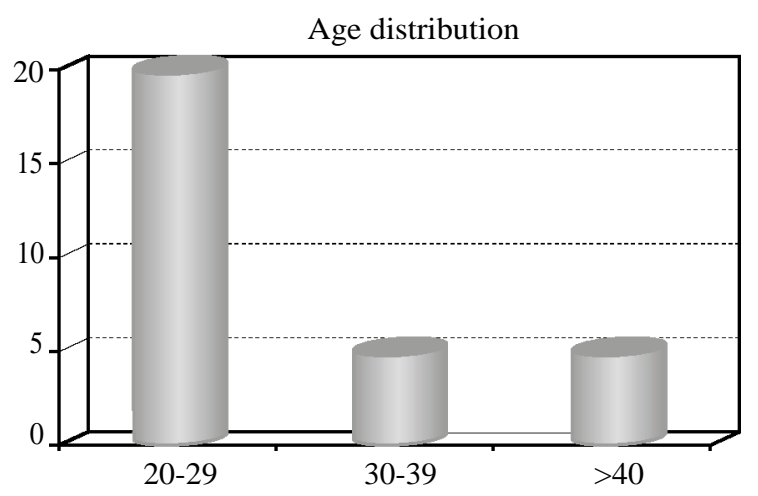

Fig. (1): Showing age distribution of cases. 


\section{Age distribution:}

The age varied from 20 to 47 years with mean age 27.8 years.

\section{Sex distribution:}

Our study concluded 18 males (70\%) and 12 female (30\%).

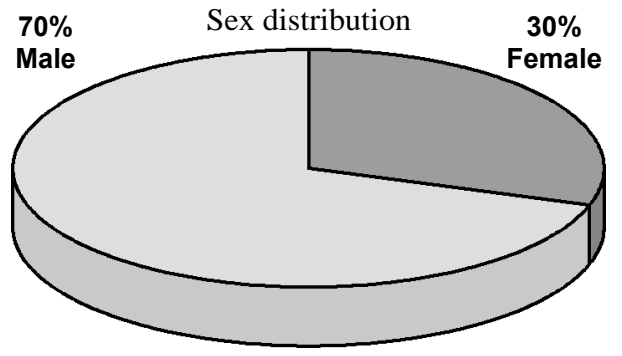

Fig. (2): Showing male to female ratio.

\section{Presenting symptoms:}

All patients were presented with sever back pain following trauma.

- They all had detailed neurological examination and all were neurologically free.

- Pain status was assessed using Denis's pain scale, 1984.

Post-operative follow-up of this study we found:

- 25 patients (83\%) were P1 (no pain).

- 5 patients (17\%) were P2 (occasional pain).

- No patient in this series reported having incapacitating pain (P3, P4 or P5).

- Poly trauma patients have pain not related to the spine.

Mechanism of injury Fig. (4): The mechanisms of injury were:

- Fall from height 10 patients $30 \%$.

- Motor car injury 20 patients $70 \%$.

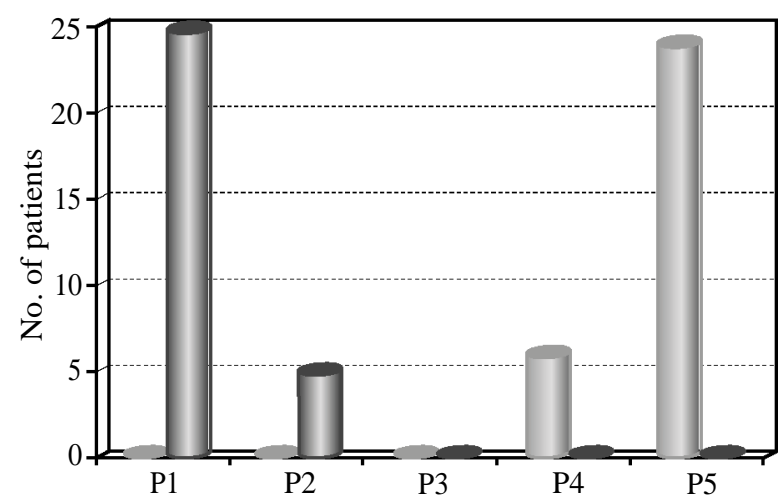

Pre-operative Post-operative

Fig. (3): Showing results of back pain.
Table (1): Pre and post-operative pain outcome.

\begin{tabular}{lcccc}
\hline \multirow{2}{*}{ Grade } & \multicolumn{2}{c}{ Pre-operative } & \multicolumn{2}{c}{ Post-operative } \\
\cline { 2 - 5 } & No. of patients & $\%$ & No. of patients & $\%$ \\
\hline P1 & - & - & 25 & 83 \\
P2 & - & - & 5 & 17 \\
P3 & & & - & - \\
P4 & 6 & 20 & - & - \\
P5 & 24 & 80 & - & - \\
\hline
\end{tabular}

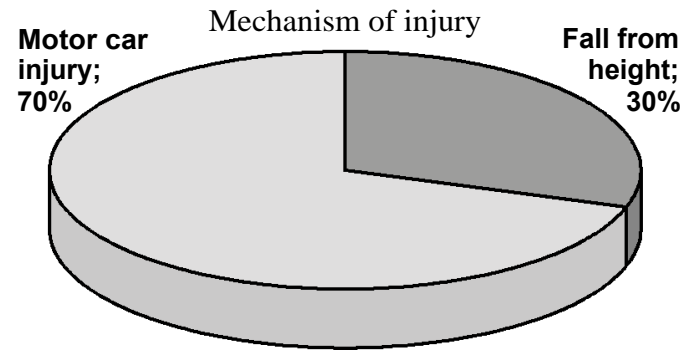

Fig. (4): Showing mechanism of injury.

Level of fracture: 28 cases $(93.3 \%)$ had only one level fracture and two patients $(6.7 \%)$ had 2adjacent levels fracture: Fracture D12: Six patient $18 \%$, Fracture L1: Ten patients 35\%, Fracture L2: Five patients 22\%, Fracture L3: Four patients 13\%, Fracture L4: Three patient 4\%, 2 level fracture D 12-L 1: One patient $4 \%$ and 2 level fracture L23: 1 patient $4 \%$.

Types of fractures: Fractures of spine were classified according to three column concept of Dines: Wedge fracture type A: 7 cases, Wedge fracture type B: 8 Cases, Burst fracture type A: 5 cases and Burst fracture type B: 10 cases.

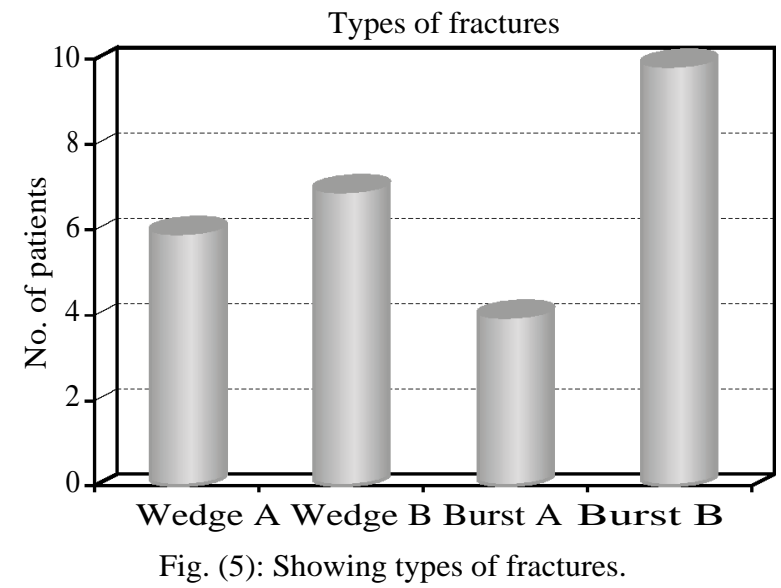

Post-operative neurological assessment:

None of our patient had neurological deterioration after surgery or during follow-up and they all were neurologically free. Tenderness over the spine: No tenderness over the spine was found on palpation in our patients. 


\section{Return to work:}

Employment status was assessed using the rating scale of Denis (Table 6). Assessment was done at 3 months follow-up: We have 24 patients $80 \%$ were $\mathrm{W} 1,4$ patients $13.3 \%$ were $\mathrm{W} 3$ due to associated fractures and 2 patients $6.7 \%$ were W5 other fractures still healing.

Table (2): Return to work outcome.

\begin{tabular}{llc}
\hline \multirow{2}{*}{$\begin{array}{l}\text { Grade of } \\
\text { work scale }\end{array}$} & \multicolumn{2}{c}{ No. of patients } \\
\cline { 2 - 3 } & Pre-operative & Post-operative \\
\hline W1 & - & $24(80 \%)$ \\
W2 & - & - \\
W3 & - & $4(13.3 \%)$ \\
W4 & - & - \\
W5 & $30(100 \%)$ & $2(67 \%)$ \\
\hline
\end{tabular}

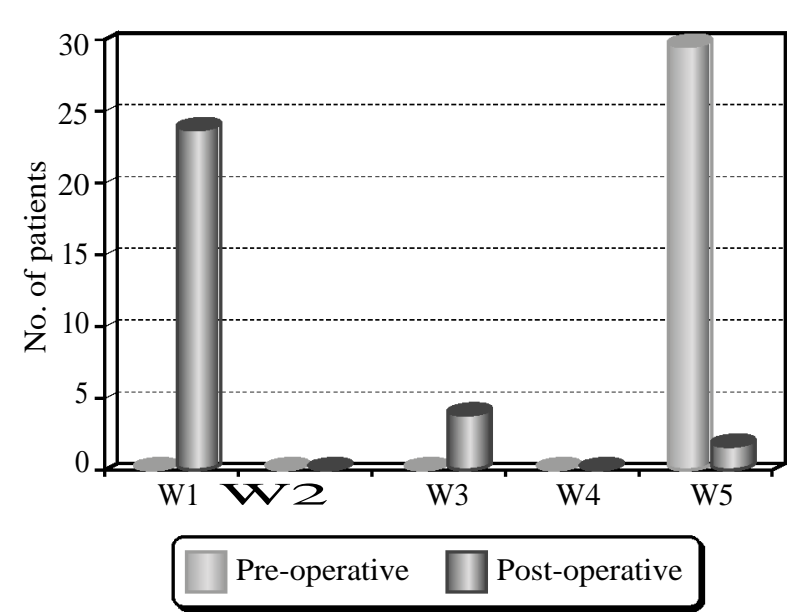

Fig. (6): Showing employment status.

\section{A- Radiological assessment:}

\section{CT scan assessment:}

The canal affection was in 16 cases $(53.3 \%)$ while in 14 cases $(51.7 \%)$ the canal was of normal size.

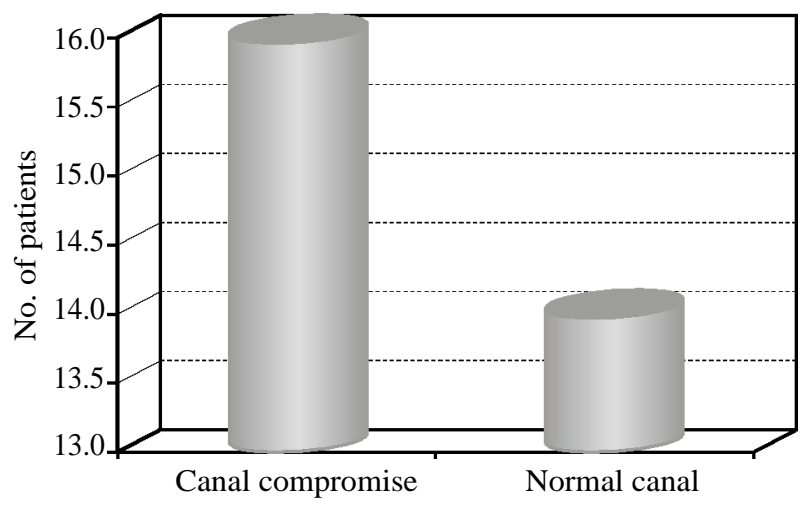

Fig. (7): CT scan assessment.

Pre-operative canal size: Average pre-operative canal compromise was $20.3 \%$ ranging from $21 \%$ to $66 \%$. The highest canal compromise was at L2 with $66 \%$. Post-operative canal size: In postoperative CT the mean percentage of canal compromise was $18.7 \%$ ranging from $10 \%$ to $58 \%$. The mean post-operative canal improvement and fragment reduction was $1.6 \%$.

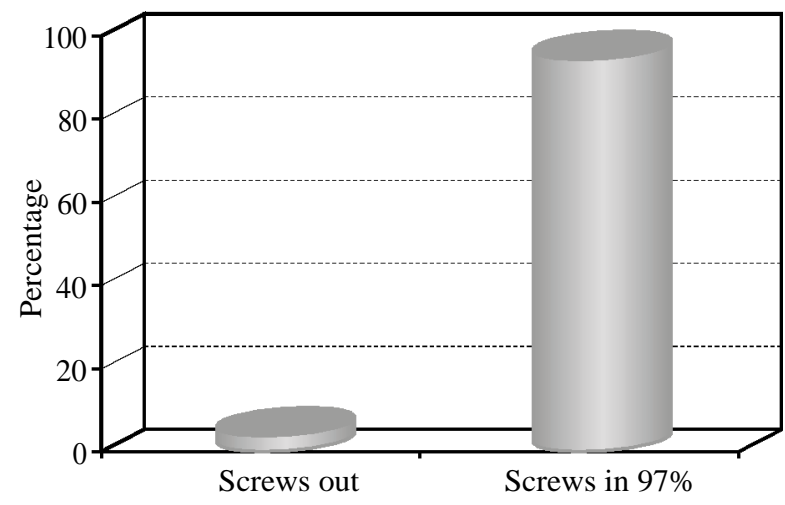

Fig. (8): Screws accuracy.

System used:

There are 21 cases fixed with Sextant system and 9 cases with WSH system. In our study we used two systems; Sextant system and WSH were Sextant system used in 21 cases $(70 \%)$ and WSH used in 9 cases $(30 \%)$.

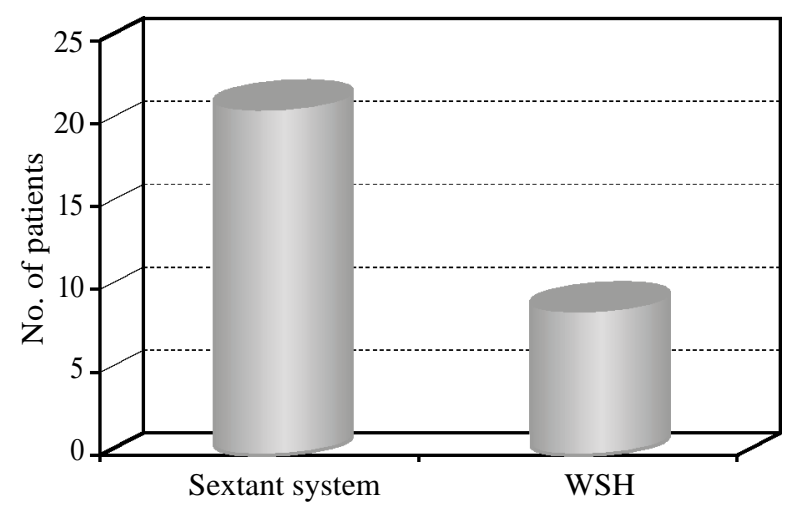

Fig. (9): System used.

Number of level fixed:

Single level fixation was in 28 cases $(93.3 \%)$.

Double level fixation was in 2 cases $(6.7 \%)$.

Number of level fixed:

- Single level fixation was in 28 cases (93.3\%).

- Double level fixation was in 2 cases $(6.7 \%)$.

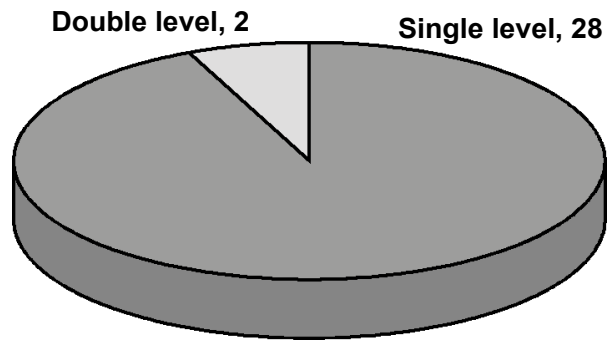

Fig. (10): Numberof level fixed. 


\section{Discussion}

This study is a prospective study of 30 consecutive patients started from June 2011 to February 2014 in Cairo University Hospital and to assess percutaneous spine fixation in thoraco-lumbar fractures.

Compared with conventional open spine surgeries, percutaneous fixation for thoraco-lumbar fractures are associated with minimal soft tissue disruption, minimal blood loss, reduced infection rate and less operative time in most cases, particularly in poly trauma patients or those with significant medical co-morbidities, complex open spine surgery may not be possible [3]. Unlike open surgery, percutaneous instrumentation can provide spinal stabilization of thoraco-lumbar injuries with a decreased perioperative morbidity rate [3].

Minimally invasive stabilization of selected spine fracture appears to be safe technique with low complication rate and high patient satisfaction. Minimally invasive stabilization reduces hospitalization and allows a fast functional recovery improving the quality of life [4].

Lior M., et al., [3] reported that open surgical technique that thoraco-lumbar spine fixation following trauma is associated with prolonged surgical time, significant blood loss, increased infection rate and approach related soft tissue and muscle destruction. In addition, patients are often afflicted with significant pain despite successful surgical recovery.

In addition conventional approach to the spine is associated with extensive blood loss, risk of wound infection and prolonged hospitalization, as well conventional extensive surgical approach in polytrauma, ICU and geriatric patient may increase their morbidity and prolong hospital stay [5]

The percutaneous system eliminates the need for a large midline incision and significant paraspinous muscle dissection. Both the pedicle screws and the precontoured rod or plate are placed through stab incisions. The paraspinous muscles are bluntly split rather than divided, leading to potentially shorter periods of hospitalization and recovery. Blood loss and tissue trauma are minimized. An ideal lateral-to-medial screw trajectory is much more easily accomplished as significant paraspinous tissue retraction is avoided [1].

This study is a prospective study of 30 consecutive patients started from June 2011 to February 2014 in Cairo University Hospital. The age varied from 20 to 47 years with mean age 27.8 years. Our study included 18 males (60\%) and 12 female $(40 \%)$.

Prafulla [6] reported fifteen consecutive patients underwent placement of percutaneous Sextant insertion during Jan. 2004 to Jun. 2005. There were ten men and five women, with ages ranged from 28 to 60 years.

Oliver et al., [7] reported 76 consecutive patients of thoracolumbar fractures stabilized by percutaneous screws following minor or major trauma from 2003 to 2007 . The mean age was 53.3 years (S.D \pm 16.9 ).

In this study the mechanisms of injury were fall from height ten patients $33.3 \%$ and motor car injury twenty patients $66.7 \%$. The types of fractures were wedge or burst fractures. There were twentytwo patients with single level fracture six patients had D12, ten patients had L1, five patients had L2, four patients had L3, three patients had L4. Two patients had two-adjacent levels fracture, one patient had D12-L1and one patient had L2-3; they all were fixed one level above and one level below.

Prafulla [6] reported that all his patients had compression fractures. All patients had a single level fixation, of which one was at L3, ten were at L4 and four were at L5.

In this study L5 fracture was excluded from the surgery because the difficulty to insert S 1 screw percutaneously and the rod or plate will stop by high L5-S1 facet joint.

Prafulla [6] operated on patients whom had unstable compression fractures.

Oliver et al., [7] reported the indication for surgery was unstable wedge and burst fractures. Patients with verified neurological affection were excluded from the study.

As regard operative time, the operative time $48 \mathrm{~min}$ ranging from minimum $25 \mathrm{~min}$ to $70 \mathrm{~min}$. Long operation time was in early cases because we used to do screw tracts one by one taking a lot of images on C-arm, later we started making 2 tracks at the same time which did shorten the time of surgery.

Petr Vanek et al., [8] reported that mean surgical time in pedicle screw group was 53 minutes plus or minus 10 minutes.

Wenfei et al., [9] reported in percutaneous pedicle screw fixation that mean operating time, the 
average operative time was 78 minutes ranging from (62min-117min).

More studies are needed to confirm necessity to remove the implant after non-fusion technique e.g. (percutaneous fixation).

\section{Conclusion:}

Plain X-ray in antero-posterior and lateral films combined with CT scan provides the best evaluation of acute thoracolumbar spine fractures. The degree of canal compromise is not an indicator of amount of neurological affection but is important to assess integrity of posterior longitudinal ligament. Percutaneous systems do not allow distraction of the fracture because there is no distraction device. Methods of partial spontaneous reduction of spine is achieved by patient positioning, screws direction, precontoured profile of rod or plate and direct manual reduction including e.g. leg hyper extension or direct sagittal manipulation of the injured segment. 2 systems where used for percutaneous spine fixation, the screw rod system (Sextent) are superior to screw plate system (WSH) because it is easy applied and can be removed from the same openings.

\section{Summary:}

Percutaneous spine fixation is a safe technique for treatment of selected thoracolumbar spinal fractures.

\section{References}

1- KEVIN T., FOLEY, M.D., SANJAY K., et al.: Percutaneous pedicle screw fixation of the lumbar spine, Neurosurg. Focus/Volume 10/April, 2001.

2- ERIC D., SCHWARTZ, FLANDERS and ADAM E.: Spinal Trauma: Imaging, Diagnosis, and Management, 1 st Edition; Lippincott Williams \& Wilkins: Chapter 7; 2007.

3- LIOR M., RAZ N., HAMUD C., et al.: Orthopedics Volume 32, Issue 4, April 2009.

4- ALESSANDRO G., MICHELE C., SIMONE C., et al.: European Spine Journal, volume 22, pp. 965-71, November 2013.

5- RECHTINE G.R., BONO P.L., CAHILL D., et al.: Postoperative wound infection after instrumentation of thoracic and lumbar fractures. J. Orthop. Trauma, 15: 566-9, 2001.

6- PRAFULLA KUMAR and SAHOO M Ch.: Percutaneous Pedicle Screw and Rod Insertion for Fracture of the Lumbar Spine; 2005.

7- OLIVER I. SCHMIDT, SERGEJ STRASSER, et al.: Role of early minimally invasive spine fixation in acute thoracic and lumbar spine trauma, IJO, October-December; 41-4, 2007.

8- PETR VANEK, ONDRE BRADAC, RENATA KONOPKOVA, et al.: Journal of Neurosurgery. Spine, Volume 75 Issue 2, pp. 162-7, 2014.

9- WEN-FEI, HUANG, YI-XING, et al.: Journal of spinal disorders and techniques, Volume 23, Issue 8, pp. 5307, December 2010.

\section{تثبيت كسور الفقرات القطنية والظهرية عن طريق الجلد}

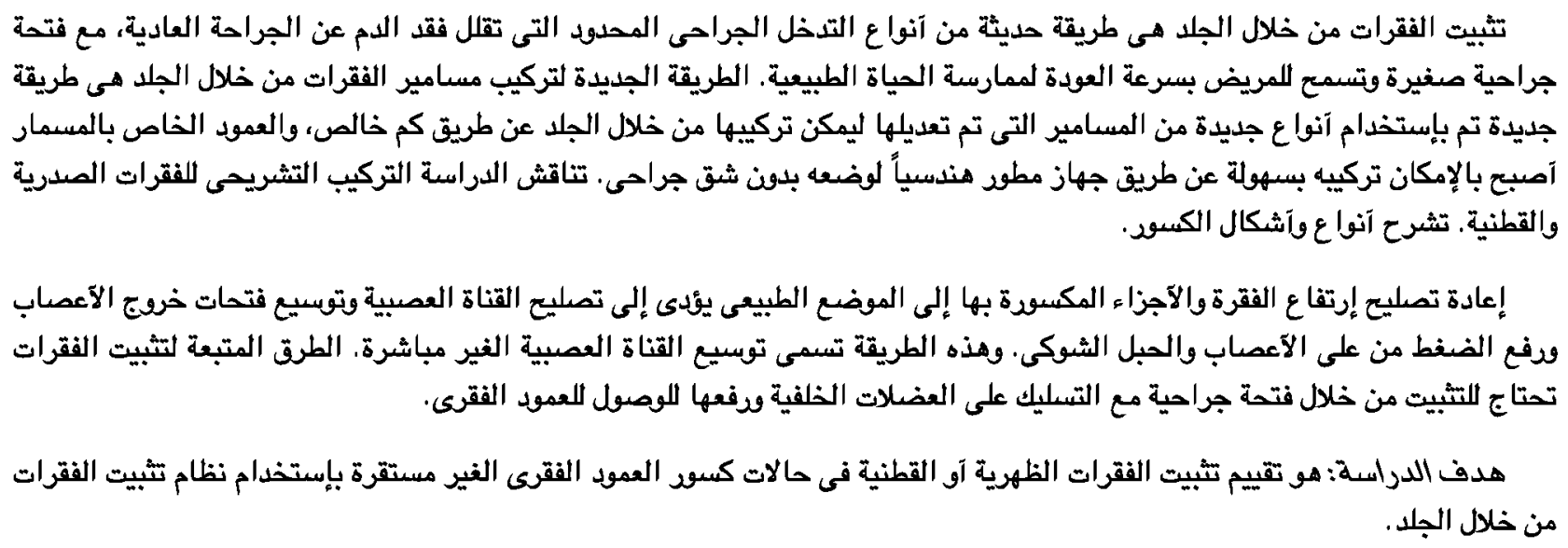

